\title{
The Inhibitory Action of Aniba Canelilla (H. B. K.) Mez. Extracts on the Corrosion of Carbon Steel in Hydrochloric Acid Medium
}

\author{
Iuri Bezerra de Barros ${ }^{a}$, Dayana Lacerda Custódio ${ }^{\text {, Mônica Calixto de Andrade }}$, \\ Valdir Florêncio da Veiga Junior ${ }^{b}$, Antônio José da Silva Neto ${ }^{a}$, Ivan Napoleão Bastos ${ }^{a}$ \\ anstituto Politécnico, Universidade do Estado do Rio de Janeiro - UERJ, Rua Bonfim, 25, CEP $28625-$ \\ 570, Nova Friburgo, RJ, Brasil \\ ${ }^{b}$ Departamento de Química, Universidade Federal do Amazonas - UFAM, Av. Rodrigo Octávio, 6200, \\ CEP 69077-000, Manaus, AM, Brasil
}

Received: August 31, 2017; Accepted: August 13, 2018

\begin{abstract}
The use of eco-friendly corrosion inhibitors in metallurgical processing has increased interest due to the reduced environmental impact. Hence, the inhibitory effect of Aniba canelilla (Lauraceae) extract was studied in the corrosion of carbon steel in $1.0 \mathrm{~mol} \cdot \mathrm{L}^{-1}$ hydrochloric acid solution. This acid is used during the surface treatment of steel processing. The carbon steel protection was observed by varying the extract concentration from 50 to $300 \mathrm{mg} \cdot \mathrm{L}^{-1}$. Polarization curves revealed that this extract acted as an adsorption inhibitor decreasing both anodic and cathodic current densities. A relatively high inhibition corrosion efficiency, close to $97 \%$, was obtained with plant stem extracts by gravimetric measurements. Weight loss measurements showed that the extract remains active for at least 72 hours at room temperature. The adsorption process of this extract is properly represented by the Langmuir isotherm. Atomic force microscopy shows that inhibited acid medium produces a smooth surface.
\end{abstract}

Keywords: Lauraceae, Polarization curve, Weight loss, Electrochemical impedance, AFM.

\section{Introduction}

Metallurgical industries use acids in thermomechanical processing and surface treatment for pickling purposes. Sulfuric and hydrochloric acids are used to remove scales present in mild steel after exposure in high temperature under oxidant environment. However, the acids must be inhibited to reduce the dissolution of metallic substrate. In this context, the search for corrosion inhibitors to protect efficiency as well as the use of chemicals less aggressive to the environment. The protective efficiency appears to increase with the presence of oxygen, nitrogen, sulfur and $\pi$ electrons in organic compounds that makes natural products a promising source. ${ }^{1-5}$ Apparently, the inhibition efficiency is linked to the polar functions that act as the reaction center of the adsorption process. ${ }^{6}$

The environmental toxicity of organic corrosion inhibitors has prompted the search for green corrosion products as they are biodegradable and do not contain heavy metals nor toxic compounds. Plant products can be inexpensive, readily available and renewable, ${ }^{4}$ as well as environmentally friendly.

Lauraceae botanical family is known to have between its metabolites several alkaloids, a natural product that present at least one nitrogen atom in a heterocyclic ring. ${ }^{7}$ Aniba canelilla (H. B. K.) Mez. belongs to Lauraceae family, and it is present in upland forests, occurring in Brazil in the states of Pará and Amazonas. It is popularly known as "casca preciosa" (precious bark in Portuguese language). A. metallic surfaces in acidic media aims higher anti-corrosion

canelilla stem produces an essential oil that is rich in 1-nitro2-phenylethane. ${ }^{8-10}$ Moreover, antioxidant and cytotoxic activities in Artemia salina were observed in this essential oil. ${ }^{11}$ The isolated 1-nitro-2-phenylethane showed analgesic activity. ${ }^{12}$ In addition to the essential oil, different isoquinoline alkaloids as reticuline, coclaurine and noranicanine have been reported in $A$. canelilla. ${ }^{13-14}$

A study with $A$. roseodora, also from Lauraceae family, shows that the alkaloid anibine acts as a corrosion inhibitor. ${ }^{15}$ Investigation of the corrosion inhibition potential of Garcinia kola, from the Clusiaceae or Guttiferae family, showed the presence of alkaloids increases the anti-corrosion effects. ${ }^{16}$

In a previous study, we described the corrosion inhibition of this extract obtained from Aniba canelilla, in carbon steel in $1.0 \mathrm{~mol} \cdot \mathrm{L}^{-1} \mathrm{H}_{2} \mathrm{SO}_{4} \cdot{ }^{17}$ The presence of alkaloids reticuline and $\mathrm{N}$-methylcoclaurine (see Figure 1) in this extract was observed by direct electron spray ionization mass spectrometry. In the present study, we evaluate the corrosion inhibition efficiency<smiles>COc1ccc(C[C@@H]2c3cc(O)c(OC)cc3CCN2C)cc1O</smiles>

reticuline<smiles>COc1cc2c(cc1O)C(Cc1ccc(O)cc1)N(C)CC2</smiles>

$N$-methylcoclaurine 
of the extract in $1.0 \mathrm{~mol} \cdot \mathrm{L}^{-1} \mathrm{HCl}$ by means of gravimetric, electrochemical and microscopy techniques.

\section{Experimental}

\subsection{Plant extract}

Aniba canelilla stems were collected in the Adolpho Ducke Forest Reserve (S 2॰57’43”, W 5955’38’, 120 m), located in Manaus City (Amazonas State, Brazil). Voucher samples are deposited at the herbarium of National Institute of Amazonian Research (INPA). The stems were dried in shade at room temperature. The plant material was extracted with ethanol by refluxing for $8.0 \mathrm{hr}$ using a Soxhlet device. After extraction, the solvent was evaporated and dried to produce a solid mass. The $A$. canelilla stem extract was stored at low temperature $\left(-4.0^{\circ} \mathrm{C}\right)$ until the corrosion tests.

\subsection{Electrochemical measurement}

The electrochemical measurements were conducted in a thermostated three-electrode cell. A silver chloride electrode $(\mathrm{Ag} / \mathrm{AgCl} 3.0 \mathrm{M})$ was used as the reference electrode and the counter electrode was a large area platinum wire. The electrolyte was $1.0 \mathrm{~mol} \cdot \mathrm{L}^{-1} \mathrm{HCl}$ prepared from concentrated reagent analytical grade (Vetec Fine Chemicals Ltda, Brazil). All experiments were performed in $200 \mathrm{~mL}$ of electrolyte under non-stirred and naturally aerated conditions. The temperature was controlled at $25.0 \pm 0.2^{\circ} \mathrm{C}$.

Carbon steel UNS G10200, hereafter termed C-steel, was used as a working electrode. The electrodes were prepared by embedding the steel rods in Teflon ${ }^{\mathrm{TM}}$ polymer and exposing a surface area of $0.33 \mathrm{~cm}^{2}$ to the electrolyte. Previously to the measurements, the sample surfaces were sanded with 600 grade emery paper under water flow, washed with double-distilled water, degreased with ethanol and dried with hot air. In all experiments, the C-steel electrode reaches its stable corrosion potential after $1,800 \mathrm{~s}$. After this period, the electrochemical impedance spectroscopy (EIS) measurement was performed over a frequency range from $20 \mathrm{kHz}$ to $10 \mathrm{mHz}$ at the corrosion potential with $8.0 \mathrm{mV}$ sine wave perturbation and 10 points per frequency decade. Subsequently, the polarization curves were performed, from the cathodic to the anodic direction, from $-300 \mathrm{mV}$ below the corrosion potential up to $300 \mathrm{mV}$ above it, with a scan rate of $1.0 \mathrm{mV} \cdot \mathrm{s}^{-1}$. All electrochemical experiments were performed in triplicate using a Gamry Reference 600 potentiostat. The equivalent electric circuit ${ }^{5}$ used to model the electrochemical reactions is exhibited in Figure 2.

The inhibition efficiency $(\eta \%)$ was calculated from potentiodynamic polarization curves and electrochemical impedance diagrams, as shown next in Eqs. (1) and (2).

$$
\eta \%=\frac{j_{\text {corr }, 0}-j_{\text {corr }}}{j_{\text {corr }, 0}} \times 100 \%
$$

$$
\eta \%=\frac{R_{c t}-R_{c t, 0}}{R_{c t}} \times 100 \%
$$

where $j_{\text {corr, } 0}$ is the corrosion current density in the absence of inhibitor, and $j_{\text {corr }}$ is the corrosion current density in the presence of inhibitor, obtained from Tafel plots, calculated as presented in Eq. (3). In this equation, E is the applied potential, $j$ is the current density close to the corrosion potential, and $\beta$ is the is the anodic and cathodic constant with units of V/ decade. Furthermore, the charge-resistance $R_{c t}$ obtained from the EIS and fitted employing an equivalent electric circuit was used to evaluate the inhibition effect. In Eq (2) where $R_{c t, 0}$ is the resistance in the absence of inhibitor, and $R_{c t}$ is the charge-resistance with inhibitor. The blank condition was $1.0 \mathrm{~mol} \cdot \mathrm{L}^{-1} \mathrm{HCl}$ (without inhibitor).

$$
E=\beta \cdot \log \left|\frac{j}{j_{\text {corr }}}\right|
$$

\subsection{Weight loss experiment}

C-steel coupons (25.0 $\mathrm{mm} \times 20.0 \mathrm{~mm} \times 1.0 \mathrm{~mm}$ ) were used in the weight loss experiment after being abraded with 100 grade emery paper under water flowing, washed with deionized water, degreased with ethanol, and dried in hot air. After this surface treatment, the samples were immersed in acid media. Triplicate specimens were immersed in the acid test solution for $24 \mathrm{hr}$ at $25^{\circ} \mathrm{C}$ in the absence and presence $\left(0,50,100,200\right.$ and $\left.300 \mathrm{mg} \cdot \mathrm{L}^{-1}\right)$ of ethanolic Aniba canelilla stem extract. After the immersion exposure, the specimens were cleaned, washed with deionized water and ethanol, dried in hot air. Weight loss was determined by gravimetric tests using an analytical balance, Ohaus AS200, with $0.1 \mathrm{mg}$ precision. The inhibition efficiency $(\eta \%)$ was determined using

$$
\eta \%=\frac{W_{0}-W}{W_{0}} \times 100 \%
$$

where $W_{0}$ and $W$ are the weight variation divided by the area and time in hours in the absence and presence of the extract, respectively.

The time and temperature effects on the corrosion rate of steel coupons in $1.0 \mathrm{~mol} \cdot \mathrm{L}^{-1} \mathrm{HCl}$ were examined. These experiments were performed in the absence and presence of $100 \mathrm{mg} \cdot \mathrm{L}^{-1}$ of ethanolic Aniba canelilla stem extract for

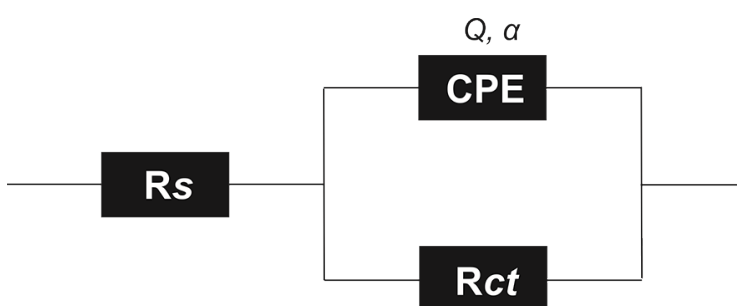

Figure 2. Equivalent circuit used to fit the EIS data of C-steel in $1.0 \mathrm{~mol} \cdot \mathrm{L}^{-1} \mathrm{HCl}$ without and with different concentrations of Aniba canelilla extract. 
24,48 and $72 \mathrm{hr}$ at $25.0^{\circ} \mathrm{C}$; and during an immersion period of $2.0 \mathrm{hr}$ at $25,35,45$ and $55^{\circ} \mathrm{C}$.

\subsection{Surface analysis}

C-steel coupons $(25.0 \mathrm{~mm} \times 20.0 \mathrm{~mm} \times 1.0 \mathrm{~mm})$ of the same alloy that was used in the electrochemical measurements were abraded with 600 grade emery paper under water flow, then washed with deionized water, degreased with ethanol, and dried in hot air for surface analysis.

The samples were immersed in $1.0 \mathrm{~mol} \cdot \mathrm{L}^{-1} \mathrm{HCl}$ in the absence and presence of $100 \mathrm{mg} \cdot \mathrm{L}^{-1}$ of ethanolic Aniba canelilla steam extract at $25^{\circ} \mathrm{C}$ for $2.0 \mathrm{hr}$. The specimens were cleaned with deionized water, dried with hot air, and then observed with an atomic force microscope (AFM), model Flex AFM with a C3000 controller (Nanosurf), in tapping mode, with a silicon probe (Tap190Al-G).

\subsection{FT-IR}

A Fourier Transform-Infrared (FT-IR) spectrometer Frontier (Perkin Elmer) equipped with the attenuated total reflectance (ATR) module device was used to analyze the Aniba canelilla extract. Typically, 32 scans were accumulated to obtain each spectrum.

\section{Results}

\subsection{Potentiodynamic polarization curve}

The open circuit potential (OCP) was monitored for $1,800 \mathrm{~s}$ of exposure in the absence and presence of Aniba canelilla extract in the following concentrations $0,50,100$, 200 and $300 \mathrm{mg} \cdot \mathrm{L}^{-1}$ (Figure 3 ) at $25^{\circ} \mathrm{C}$. Polarization curves and impedance were performed after an OCP monitoring phase. The potential variations during $1,800 \mathrm{~s}$ were small, and the OCP of inhibited media was approximately $15 \mathrm{mV}$ above the non-inhibited acid.

In the potentiodynamic polarization curves (Figure 4), the presence of Aniba canelilla extract leads to a decrease in both anodic and cathodic current densities. These results could be assigned to the adsorption of organic compounds present in the extracts at the active sites of the surface, which limit the metallic dissolution and the hydrogen evolution, and consequently slows down the corrosive process. Similar polarization results from different inhibitors were also ascribed to the adsorption of compounds.;15

The electrochemical parameters of corrosion potential $\left(E_{\text {corr }}\right)$, corrosion current density $\left(\mathrm{j}_{\text {corr }}\right)$, and anodic $\left(\beta_{a}\right)$ and cathodic $\left(\beta_{c}\right)$ constants are shown in Table 1 . They were obtained by fitting the Tafel plots. Corrosion potential variations higher than $85 \mathrm{mV}$ relative to the blank condition is considered to identify an inhibitor as having anodic or cathodic action. ${ }^{18}$ However, no significant deviation was observed in $E_{\text {corr }}$, hence demonstrating that Aniba canelilla

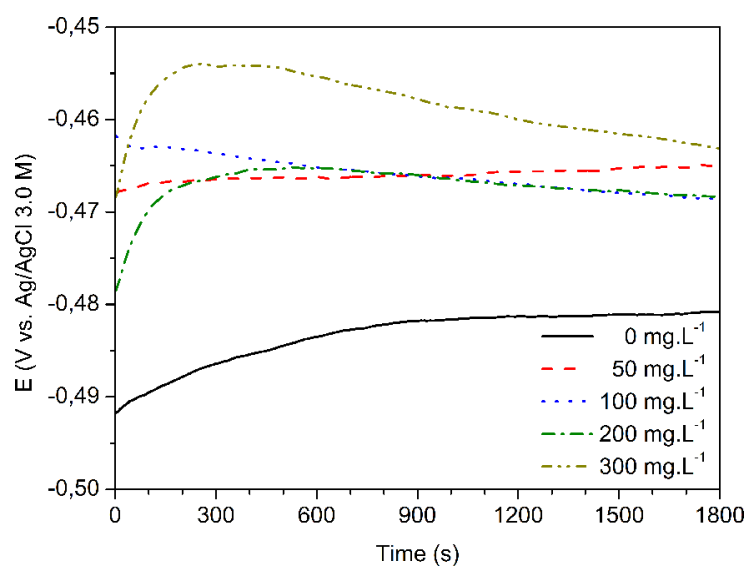

Figure 3. Open circuit potential of C-steel in $1.0 \mathrm{~mol} \cdot \mathrm{L}^{-1} \mathrm{HCl}$ Aniba canelilla stem extract at the concentrations 0, 50, 100, 200 and $300 \mathrm{mg} \cdot \mathrm{L}^{-1}$.

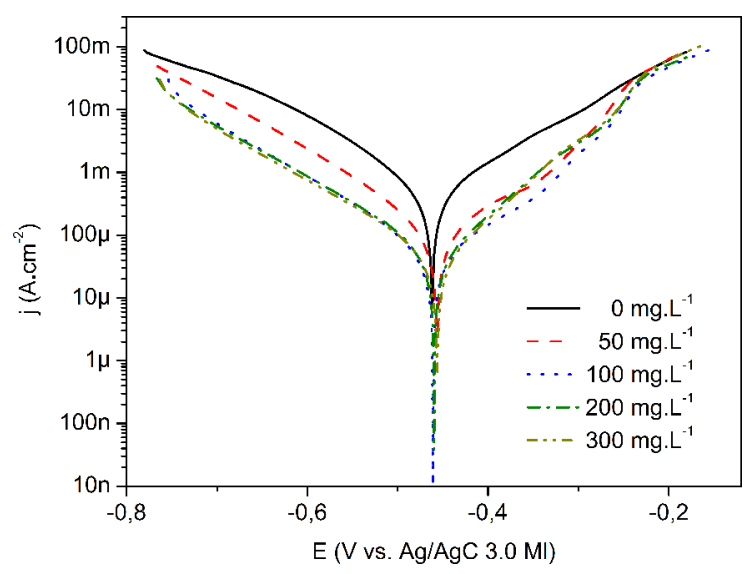

Figure 4. Polarization curves of $\mathrm{C}$-steel in $1.0 \mathrm{~mol} \cdot \mathrm{L}^{-1} \mathrm{HCl}$ without and with ethanolic Aniba canelilla extract at 0, 50, 100, 200 and $300 \mathrm{mg} \cdot \mathrm{L}^{-1}$ at $25.0^{\circ} \mathrm{C}$.

extract acts as a mixed-type inhibitor. The efficiency increases with the inhibitor content.

\subsection{Electrochemical impedance spectroscopy (EIS)}

Figure 5 illustrates the Nyquist plots of C-steel in a 1.0 $\mathrm{mol} \cdot \mathrm{L}^{-1} \mathrm{HCl}$ with and without ethanolic Aniba canelilla extract at $25.0^{\circ} \mathrm{C}$. All diagrams present a high frequency capacitive loop whose size increases with the inhibitor content. Moreover, a small inductive loop exists for the non-inhibited medium, probably related to adsorbed species. The steel tested without inhibitor exhibits the smallest size diagram.

The $\left|Z_{i}\right|$ vs. frequency plot on a logarithmic scale (Figure 6) provides an insight into the experiment system. The slopes at low and high frequencies are $+\alpha$ and $-\alpha$. At higher frequencies we have a larger number of points, and with these data the $\alpha$ value was determined (Table 2). When this value differs from unity, a constant phase element (CPE) can be used to fit the impedance spectra. The parameter $\alpha$ can be calculated as shown in Eq. (5). This graphical method 
Table 1. Kinetic parameters obtained from Tafel plots for C-steel in $1.0 \mathrm{~mol} \cdot \mathrm{L}^{-1} \mathrm{HCl}$ without and with ethanolic Aniba canelilla extract at the following concentrations: $0,50,100,200$ and $300 \mathrm{mg} \cdot \mathrm{L}^{-1}$ at $25.0{ }^{\circ} \mathrm{C}$.

\begin{tabular}{lccccc}
\hline $\begin{array}{l}\text { Concentration } \\
\left(\mathbf{m g} \cdot \mathbf{L}^{-1}\right)\end{array}$ & $\begin{array}{c}\mathbf{E}_{\text {corr }}(\mathbf{m V ~ v s . ~} \mathbf{A g} / \\
\mathbf{A g C l})\end{array}$ & $\mathbf{j}_{\text {corr }}\left(\boldsymbol{\mu} \mathbf{A} \cdot \mathbf{c m}^{-2}\right)$ & $\boldsymbol{\beta}_{\mathbf{a}}(\mathbf{m V} / \mathbf{d e c})$ & $\boldsymbol{- \beta}_{\mathbf{c}}(\mathbf{m V} / \mathbf{d e c})$ & $\boldsymbol{\eta} \%$ \\
\hline 0 & $-461.0 \pm 7.2$ & $880.3 \pm 44.9$ & $176.3 \pm 51.4$ & $160.7 \pm 36.4$ & - \\
50 & $-456.3 \pm 6.7$ & $105.8 \pm 13.6$ & $112.6 \pm 13.6$ & $126.5 \pm 5.2$ & $88.0 \pm 1.5$ \\
100 & $-462.3 \pm 15.8$ & $74.2 \pm 3.5$ & $130.0 \pm 34.5$ & $139.6 \pm 14.2$ & $91.6 \pm 0.4$ \\
200 & $-460.0 \pm 3.5$ & $62.9 \pm 3.3$ & $119.0 \pm 12.6$ & $115.8 \pm 0.80$ & $92.9 \pm 0.4$ \\
300 & $-455.7 \pm 0.6$ & $52.3 \pm 2.6$ & $99.6 \pm 1.6$ & $127.0 \pm 12.4$ & $94.1 \pm 0.3$ \\
\hline
\end{tabular}

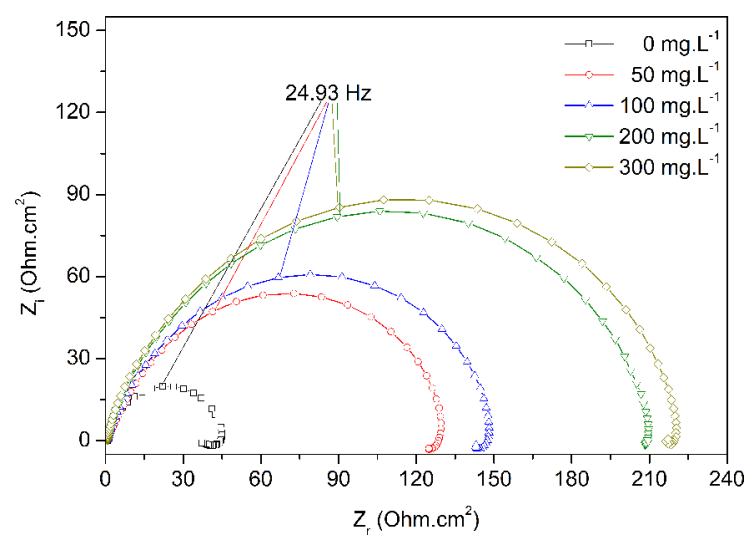

Figure 5. Nyquist plots obtained at the corrosion potential for $\mathrm{C}$-steel in $1.0 \mathrm{~mol} \cdot \mathrm{L}^{-1} \mathrm{HCl}$ without and with the ethanolic Aniba canelilla extract at $25.0^{\circ} \mathrm{C}$. Concentrations: $0,50,100,200$ and $300 \mathrm{mg} \cdot \mathrm{L}^{-1}$.

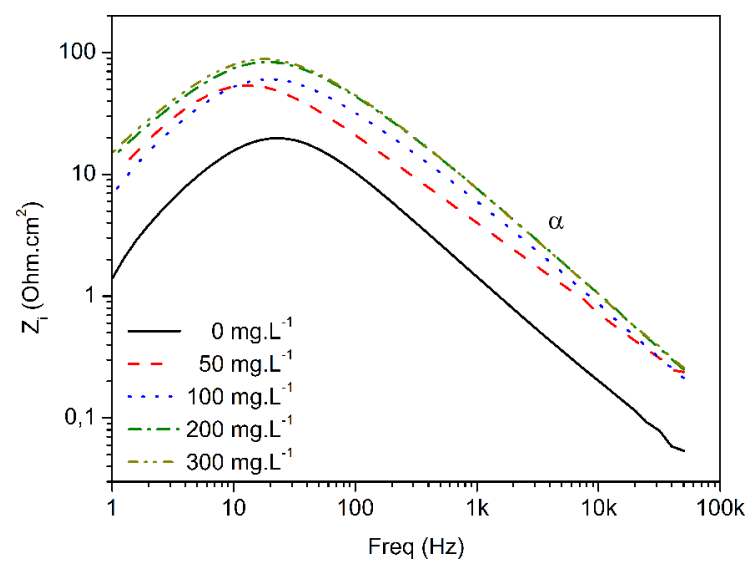

Figure 6. Imaginary part of the impedance as a function of frequency at $25.0^{\circ} \mathrm{C}$.

Table 2. Values of $\alpha$ graphically determined.

\begin{tabular}{lc}
\hline Inhibitor $\left(\mathbf{m g} \cdot \mathbf{L}^{-1}\right)$ & $\alpha_{\text {graphical }}$ \\
\hline 0 & $0.837 \pm 0.024$ \\
50 & $0.724 \pm 0.004$ \\
100 & $0.794 \pm 0.008$ \\
200 & $0.806 \pm 0.015$ \\
300 & $0.827 \pm 0.003$ \\
\hline
\end{tabular}

is direct, not affected by the simultaneous fitting of other parameters, and does not use the electrolyte resistance to correct the modulus.

$$
\alpha=\left|\frac{\Delta \log \left|Z_{i}\right|}{\Delta \log f}\right|
$$

Taking into account the results of Table 2, a CPE is introduced in the circuit instead of a pure double layer capacitor in order to yield a more accurate fit. ${ }^{19}$ It is worth mentioning that the double layer capacitance value can be affected by the surface heterogeneity, as well as other phenomena. ${ }^{20}$ The CPE impedance, which is present in Figure 2, is expressed by the following expression:

$$
Z_{C P E}=\frac{1}{Q(i \cdot \omega)^{\alpha}}
$$

where $Q$ is the magnitude of the CPE, with $-1 \leq \alpha \leq 1$, and $\omega$ is the angular frequency. The capacitive loops have depressed semi-circular appearance, $0.5 \leq \alpha \leq 1.0$, as a result of the physical inhomogeneity or the roughness of the solid surface. ${ }^{20-22}$ In Eq. (6) $i$ is the imaginary number $\left(i^{2}=-1\right)$. The exponent value makes it possible to identify the behavior of a CPE $(0 \leq \alpha \leq 1)$ from that of an ideal capacitor $\alpha=1$.

The EIS spectra were analyzed using the equivalent circuit (Figure 2), where $\mathrm{R}_{\mathrm{S}}$ represents the ohmic resistance of the solution and $R_{c t}$ the charge transfer resistance whose value measures the electron transfer across the surface and is inversely proportional to corrosion rate.

The impedance parameters, including $\mathrm{R}_{c t}, \mathrm{Q}$ and $\alpha$ obtained from fitting the recorded EIS data using the equivalent circuit of Figure 2, are listed in Table 3, along with the percentage of inhibition efficiency $(\eta \%)$. It is clear that the $R_{c t}$ values increase with inhibitor concentration increase. The adsorption of some molecules present in the extract onto the metal/solution interface may justify these results. Indeed, this hypothesis is corroborated by the anodic and cathodic polarization curves, and the corrosion potential results. The inhibition efficiency values $(\eta \%)$, calculated from $R_{c t}$ data in the absence and presence of the extract, for the highest concentration was $82.0 \pm 1.9 \%$.

\subsection{Weight loss}

The results of weight loss measurements for the corrosion of C-steel in $1.0 \mathrm{~mol} \cdot \mathrm{L}^{-1} \mathrm{HCl}$ without and with ethanolic Aniba canelilla extract in different concentrations $(0,50$, 
Table 3. Electrochemical parameters obtained from EIS plots for C-steel in $1.0 \mathrm{~mol} \cdot \mathrm{L}^{-1} \mathrm{HCl}$ without and with ethanolic Aniba canelilla extract at the following concentrations: $0,50,100,200$ and $300 \mathrm{mg} \cdot \mathrm{L}^{-1}$.

\begin{tabular}{lccccc}
\hline Inhibitor $\left(\mathbf{m g} \cdot \mathbf{L}^{-1}\right)$ & $\mathbf{R}_{\mathrm{ct}}\left(\mathbf{O h m} \cdot \mathbf{c m}^{2}\right)$ & $\boldsymbol{\alpha}$ & $Q\left(\boldsymbol{\mu} \mathbf{M h o} \cdot \mathbf{c m}^{-2}\right)$ & $\mathbf{f}_{\max }(\mathbf{H z})$ & $\boldsymbol{\eta} \%$ \\
\hline 0 & $37.7 \pm 0.4$ & $0.8509 \pm 0.0025$ & $333.94 \pm 0.1$ & 24.93 & - \\
50 & $130.7 \pm 0.2$ & $0.7884 \pm 0.0005$ & $223.1 \pm 13.4$ & 15.83 & $70.1 \pm 0.1$ \\
100 & $151.6 \pm 6.3$ & $0.8384 \pm 0.0055$ & $106.8 \pm 5.5$ & 19.86 & $74.2 \pm 1.0$ \\
200 & $201.5 \pm 0.1$ & $0.8430 \pm 0.0102$ & $87.5 \pm 1.2$ & 19.86 & $81.5 \pm 1.2$ \\
300 & $220.9 \pm 2.4$ & $0.8323 \pm 0.0375$ & $75.5 \pm 1.7$ & 19.86 & $82.0 \pm 1.9$ \\
\hline
\end{tabular}

100,200 and $300 \mathrm{mg} \cdot \mathrm{L}^{-1}$ ) for $24 \mathrm{hr}$, at $25.0^{\circ} \mathrm{C}$, are depicted in Table 4. Again, the percentage of inhibition efficiency $\eta \%$ increases with the extract concentration, but shows no significant change in concentrations higher than $100 \mathrm{mg} \cdot \mathrm{L}^{-1}$, reaching an efficiency around $97 \%$.

The results of the weight loss measurements for the corrosion of $\mathrm{C}$-steel in $1.0 \mathrm{~mol} \cdot \mathrm{L}^{-1} \mathrm{HCl}$ without and with $100 \mathrm{mg} \cdot \mathrm{L}^{-1}$ of ethanolic Aniba canelilla extract for different immersion times $(24,48$ and $72 \mathrm{hr})$ are provided in Table 5. These tests demonstrate the stability of the extract versus time exposure. The C-steel corrosion rate was reduced with the addition of the extract for all immersion times. It is noted a slight variation in the efficiency $\eta \%$ with time, from $96.00 \%$ to $96.95 \%$ after 24 and $72 \mathrm{hr}$ of immersion, indicating that the inhibition efficiency remains after long periods of immersion.

The effects of temperature on the corrosion of C-steel in $1.0 \mathrm{~mol} \cdot \mathrm{L}^{-1} \mathrm{HCl}$ without or with $100 \mathrm{mg} \cdot \mathrm{L}^{-1}$ of ethanolic Aniba canelilla extract ranging from 25 to $55^{\circ} \mathrm{C}$ after $2.0 \mathrm{hr}$ of immersion time are presented in Figure 7 . The corrosion rates of the steel in both media increased with the temperature. The inhibition efficiency of the ethanolic Aniba canelilla, which modifies on 0 and $100 \mathrm{mg} \cdot \mathrm{L}^{-1}$ weight loss evaluations, shows a slight increase with temperature.

Table 4. C-steel weight loss data in $1.0 \mathrm{~mol} \cdot \mathrm{L}^{-1} \mathrm{HCl}$ with and without ethanolic Aniba canelilla stem extract at the following concentrations: $0,50,100,200$ and $300 \mathrm{mg} \cdot \mathrm{L}^{-1}$.

\begin{tabular}{lcc}
\hline Inhibitor $\left(\mathbf{m g} \cdot \mathbf{L}^{-1}\right)$ & $\begin{array}{c}\mathbf{W}_{\mathbf{c o r r}}\left(\mathbf{m g} \cdot \mathbf{c m}^{-}\right. \\
\left.\mathbf{2}_{\mathbf{h r}} \mathbf{~}\right)\end{array}$ & $\boldsymbol{\eta} \%$ \\
\hline 0 & $1.181 \pm 0.032$ & - \\
50 & $0.300 \pm 0.003$ & $74.60 \pm 2.31$ \\
100 & $0.036 \pm 0.004$ & $96.95 \pm 2.32$ \\
200 & $0.035 \pm 0.002$ & $97.04 \pm 2.30$ \\
300 & $0.036 \pm 0.002$ & $96.95 \pm 2.30$ \\
\hline
\end{tabular}

Table 5. C-steel weight loss data in $1.0 \mathrm{~mol} \cdot \mathrm{L}^{-1} \mathrm{HCl}$ without and with $100 \mathrm{mg} \cdot \mathrm{L}^{-1}$ of ethanolic Aniba canelilla extract at the following immersion times: 24,48 and $72 \mathrm{hr}$ at $25{ }^{\circ} \mathrm{C}$.

\begin{tabular}{llcl}
\hline \multirow{2}{*}{$\begin{array}{l}\text { Immersion } \\
\text { time (hr) }\end{array}$} & \multicolumn{2}{c}{$\mathbf{W}_{\text {corr }}\left(\mathbf{m g} \cdot \mathbf{c m}^{-2} \cdot \mathbf{h r}^{-1}\right)$} & \multirow{\eta}{*}{$\boldsymbol{\eta} \%$} \\
\cline { 2 - 3 } & Without & With & \\
\hline 24 & $1.181 \pm 0.032$ & $0.036 \pm 0.004$ & $96.95 \pm 2.32$ \\
48 & $0.575 \pm 0.024$ & $0.023 \pm 0.001$ & $96.00 \pm 7.26$ \\
72 & $0.759 \pm 0.011$ & $0.025 \pm 0.001$ & $96.71 \pm 1.91$ \\
\hline
\end{tabular}

Moreover, the apparent activation energy for C-steel corrosion in pure $\mathrm{HCl}$ solution and in inhibiting acid media was determined from an Arrhenius-type plot according to Eq. (7):

$$
\log W_{\text {corr }}=\frac{-E_{a}}{2.303 \cdot R \cdot T}+\log A
$$

where $W_{\text {corr }}$ is the corrosion rate, $E_{a}$ is the apparent activation energy, $A$ is the pre-exponential factor, $T$ is the absolute temperature and $\mathrm{R}$ is the molar gas constant. Arrhenius plots of $\left(\log W_{\text {corr }}\right)$ vs. $(1 / T)$ for C-steel in $1.0 \mathrm{~mol} \cdot \mathrm{L}^{-1} \mathrm{HCl}$ both in the absence and presence of the ethanolic Aniba canelilla extract are shown in Figure 7.

The apparent activation energy obtained for the corrosion process in the free acid solution was found to be $38.3 \mathrm{~kJ} \cdot \mathrm{mol}^{-1}$, and $60.0 \mathrm{~kJ} \cdot \mathrm{mol}^{-1}$ in the presence of the inhibitor. The energy barrier for the corrosion reaction increased in the inhibitor presence. An increase in inhibition efficiency with rise in temperature and lower activation energy in the presence of inhibitor suggests a chemisorption mechanism. On the other hand, a decrease in inhibition efficiency with rise of temperature, with an analogous increase in corrosion activation energy in the presence of inhibitor compared to the situations with its absence, is frequently interpreted as being a formation of an adsorption film of physical nature..$^{23-25}$ Here, we observed the higher activation energy in the presence of inhibitor and also noticed a slight growth on the inhibition efficiency with increasing temperature. Due to the great diversity of molecules present in the Aniba canelilla

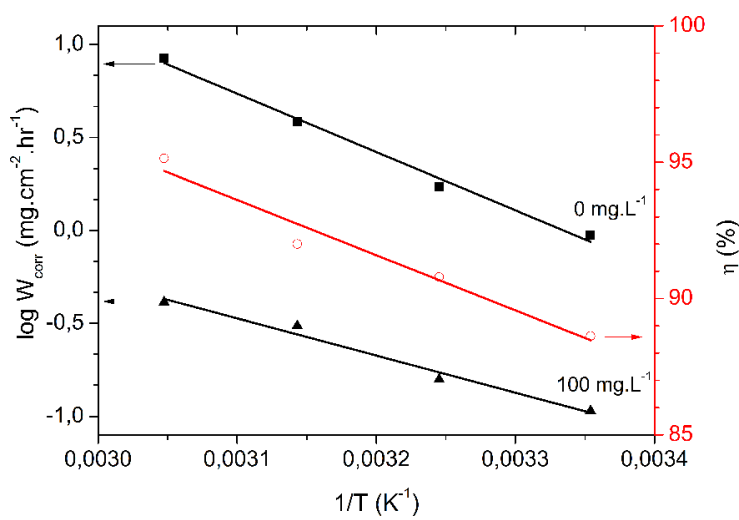

Figure 7. Arrhenius plot for the $\mathrm{C}$-steel corrosion rate in 1.0 $\mathrm{mol} \cdot \mathrm{L}^{-1} \mathrm{HCl}$ in absence and presence of $100 \mathrm{mg} \cdot \mathrm{L}^{-1}$ of ethanolic Aniba canelilla extract. 
extract, the inhibition mechanism is most likely complex, involving both chemical and physical processes, as shown by the polarization curves in Figure 4. A similar behavior was observed with the seed extract of Retama monosperma (L.), which is rich in alkaloids. ${ }^{26}$

\subsection{Adsorption isotherm}

The fitting of the obtained data to the Langmuir isotherm is illustrated by plotting according to Eq. (8). In this equation, $C$ is the concentration, $\theta$ the occupied fraction of surface and $\mathrm{K}$ the adsorption constant (Figure 8). The adjustment of the Langmuir adsorption isotherm was very good, with a correlation factor $r^{2}$ close to 0.996 . This behavior suggests that compounds present in the ethanolic Aniba canelilla extract were adsorbed onto the C-steel surface according to a Langmuir adsorption isotherm, indicating the absence of interaction forces amongst adsorbed molecules.

$$
\frac{C}{\theta}=C+\frac{1}{K}
$$

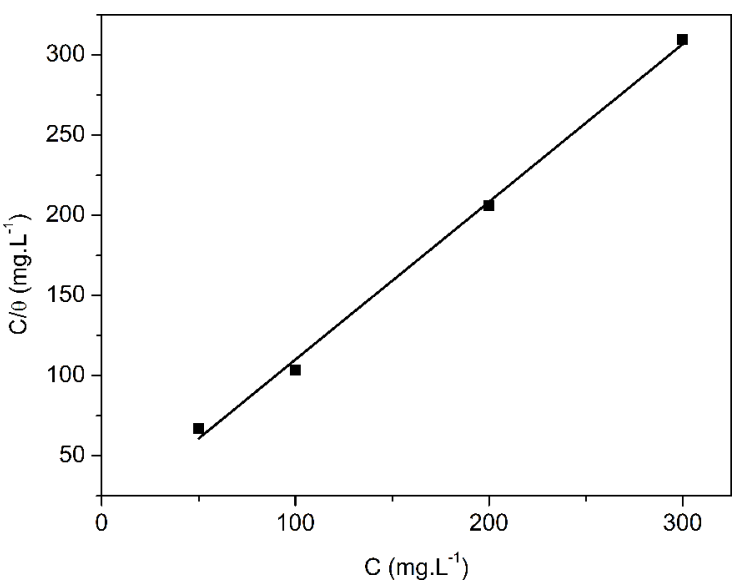

Figure 8. Langmuir adsorption isotherm of ethanolic Aniba canelilla extract on the $\mathrm{C}$-steel surface in $1.0 \mathrm{~mol} \cdot \mathrm{L}^{-1} \mathrm{HCl}$.

\subsection{Surface analysis}

The two dimensional AFM images of C-steel surface are shown in Figure 9. The Figure 9A shows that the C-steel surface before immersion seems smoother and still holds some abrading scratches on the horizontal direction. As for Figure $9 \mathrm{~B}$, the C-steel surface after immersion in $1.0 \mathrm{~mol} \cdot \mathrm{L}^{-1} \mathrm{HCl}$ for $2.0 \mathrm{hr}$ was damaged strongly as compared with Figure 9A. Figure 9C exhibits that there is a protective effect due to an adsorbed film on the steel surface in the presence of $100 \mathrm{mg} \cdot \mathrm{L}^{-1}$ Aniba canelilla extract.

The three-dimensional AFM images are shown in Figure 10. It can be seen from Figure 10A that the C-steel surface before immersion seems smooth compared to the C-steel surface after immersion in uninhibited $1.0 \mathrm{~mol} \cdot \mathrm{L}^{-1} \mathrm{HCl}$ for $2.0 \mathrm{hr}$. The maximum height of roughness of sanding $\mathrm{C}$-steel sample (Figure 10A) and C-steel in $1.0 \mathrm{~mol} \cdot \mathrm{L}^{-1} \mathrm{HCl}$ without inhibitor (Figure 10B) was calculated to be $1.17 \mathrm{~nm}$ and $20.4 \mathrm{~nm}$, respectively. It is clearly shown in Figure 10B that $\mathrm{C}$-steel sample is attacked by the hydrochloric acid. However, in the presence of higher concentration of inhibitor, the average roughness was reduced to $16.9 \mathrm{~nm}$ (Figure 10C). The roughness profile of the AFM images across the diagonals of the sample observed area is presented in Figure 11. The acid attacks the metal producing a rougher surface, as can be seen by comparing the sanded and corroded profiles of Figure 11. Nonetheless, it is evident that in the presence of inhibitor $\left(100 \mathrm{mg} \cdot \mathrm{L}^{-1}\right)$ the corrosion of the sample was quite reduced and the smooth profile also reveals this behavior.

\subsection{FT-IR analyses}

The plant stem extract was analyzed by FT-IR spectroscopy (Figure 12). The peak at $3348 \mathrm{~cm}^{-1}$ can be assigned to the stretching mode of O-H and/or N-H. The peaks at 2920 and $2851 \mathrm{~cm}^{-1}$ can be assigned to aliphatic $\mathrm{C}-\mathrm{H}$ groups. The peaks at 1270 and $1119 \mathrm{~cm}^{-1}$ can be assigned to C-N linkage in aromatic and aliphatic systems. The FT-IR peaks at 1704 , 1607,1516 and $1455 \mathrm{~cm}^{-1}$ correspond to $\mathrm{C}=\mathrm{O}, \mathrm{R}_{2} \mathrm{C}=\mathrm{N}$ and $\mathrm{C}=\mathrm{C}$. Moreover, Chauhan et al. ${ }^{27}$ and Abboud et al. ${ }^{28}$ also
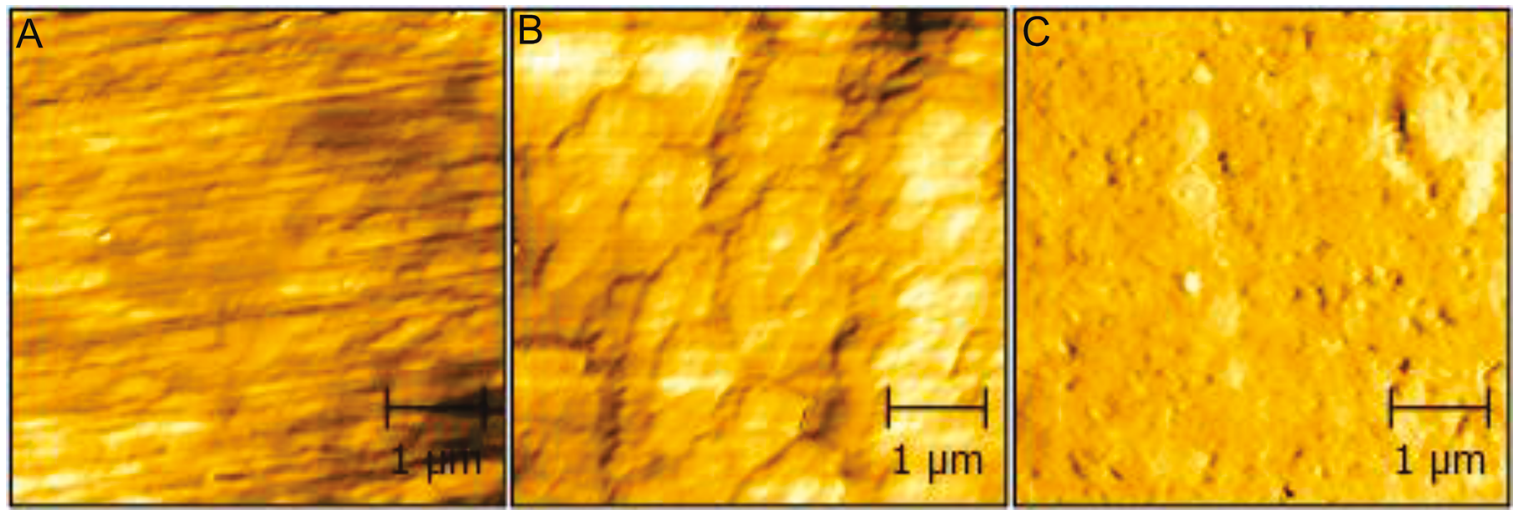

Figure 9. AFM images of C-steel surface topography at $25^{\circ} \mathrm{C}$ : (A) before immersion; (B) after $2.0 \mathrm{hr}$ of immersion in $1.0 \mathrm{~mol} \cdot \mathrm{L}^{-1} \mathrm{HCl}$; (C) after $2.0 \mathrm{hr}$ of immersion in inhibited acid solution $\left(1.0 \mathrm{~mol} \cdot \mathrm{L}^{-1} \mathrm{HCl}+100 \mathrm{mg} \cdot \mathrm{L}^{-1}\right.$ Aniba canelilla extract). 


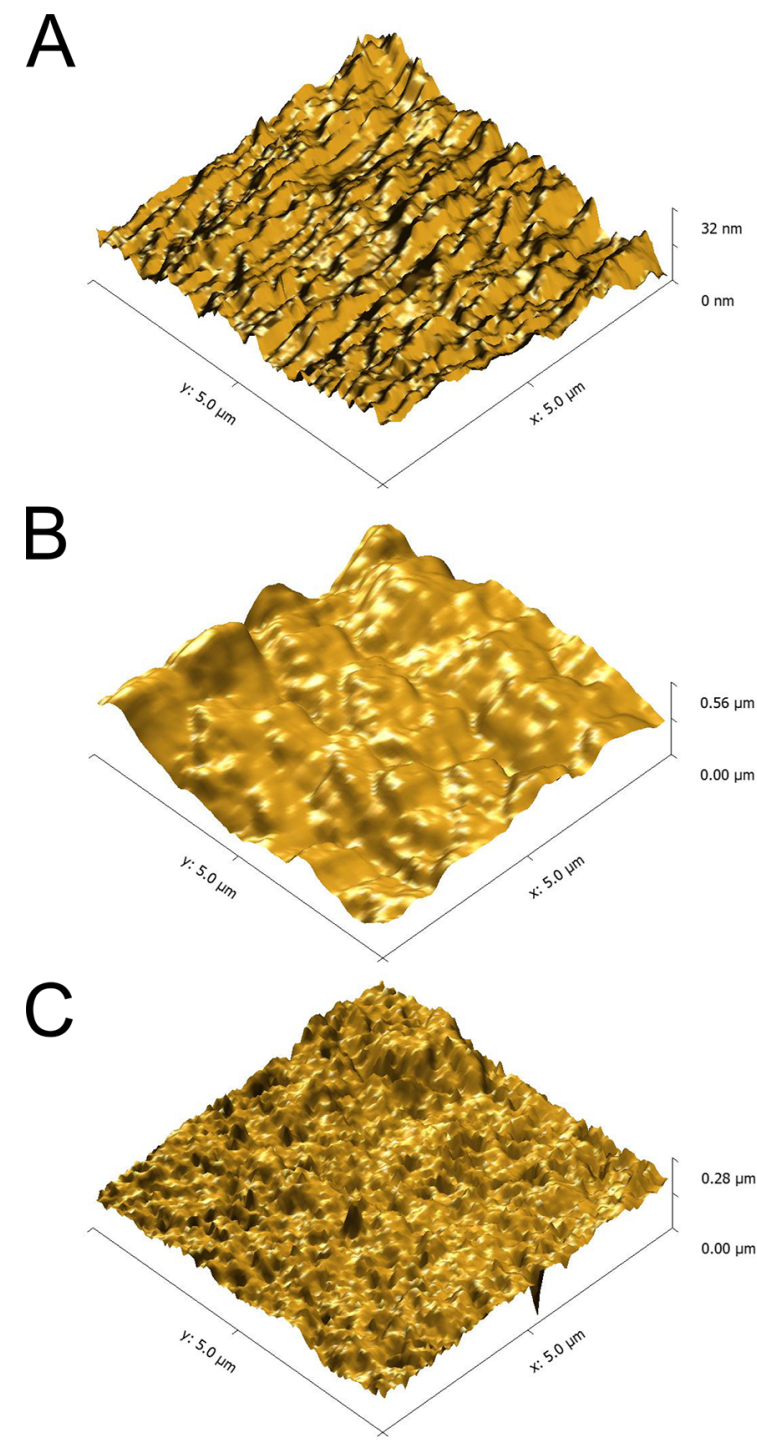

Figure 10. AFM images of C-steel surface at $25^{\circ} \mathrm{C}$ : (A) before immersion; (B) after $2.0 \mathrm{hr}$ of immersion in $1.0 \mathrm{~mol} \cdot \mathrm{L}^{-1} \mathrm{HCl}$; (C) after $2.0 \mathrm{~h}$ of immersion in inhibited acid solution $\left(1.0 \mathrm{~mol} \cdot \mathrm{L}^{-1} \mathrm{HCl}\right.$ $+100 \mathrm{mg} \cdot \mathrm{L}^{-1}$ Aniba canelilla extract).

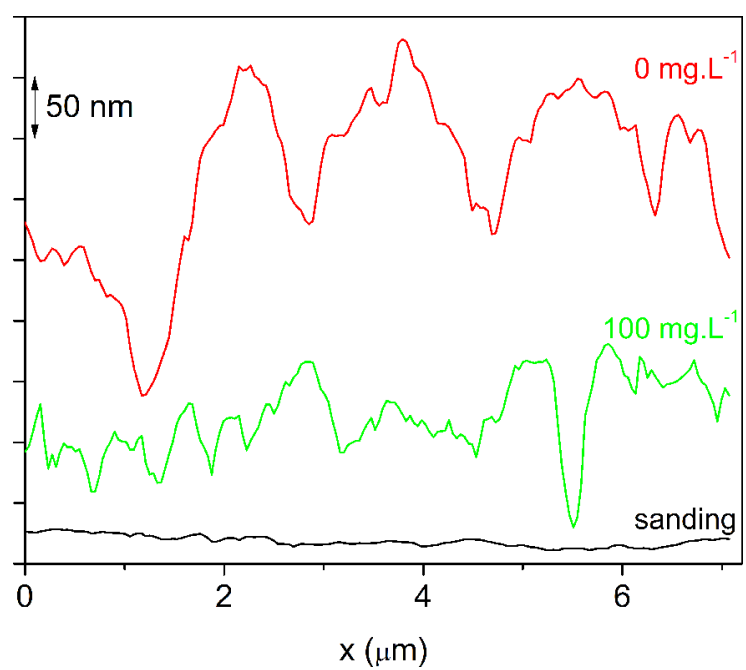

Figure 11. Surface roughness profile across the sample diagonals measured with AFM.

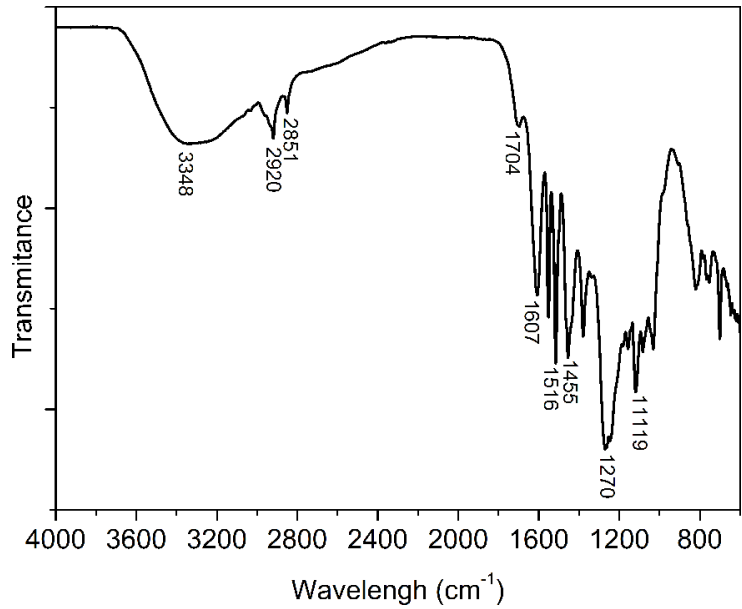

Figure 12. FT-IR spectra of Aniba canelilla extract.

observed on the metal surface molecules with polar groups such as those identified by FT-IR for the extract. Likely the presence of these groups act to inhibit the corrosion in acid medium with Aniba canelilla extracts.

\section{Conclusions}

The Aniba canelilla (Lauraceae) extract is an efficient inhibitor on carbon steel in hydrocloric acid medium (1.0 $\mathrm{mol} \cdot \mathrm{L}^{-1} \mathrm{HCl}$ ) at $25^{\circ} \mathrm{C}$. Moreover:

1. The results found in polarization measurements suggest that the inhibitor compound adsorbs on carbon steel surface. A concentration-dependent reduction of both the anodic and cathodic current densities was observed.

2. EIS confirms the behavior seen in the polarization curves, showing an inhibition efficiency gain with increasing extract concentration.

3. The adsorption process followed a Langmuir adsorption isotherm from weight loss measurements. Moreover, a high inhibition efficiency, close to $97 \%$, was obtained with the plant stem extracts by gravimetric procedure.

4. AFM analyses confirmed the protective effect of inhibited solutions by the smooth profile of the samples submitted to inhibited hydrochloric media.

5. The inhibitory efficiency of the extract remained stable at least up to 72 hours at room temperature.

\section{Acknowledgements}

The authors acknowledge the financial support provided by the Brazilian Agencies FAPERJ (E26/110.644/2012), CAPES and CNPq. We also thank Mr. Emandro V. da Costa for obtaining the AFM images. 


\section{References}

1. Gece G. Drugs: A review of promising novel corrosion inhibitors. Corrosion Science. 2011;53(12):3873-3898.

2. Mobin M, Masroor S. Alkanediyl-a, $\omega$-bis (dimethyl cetylammoniaum bromide) gemini surfactants as novel corrosion inhibitors for mild steel in formic acid. Materials Research. 2012;15(6):837847.

3. Pereira SSAP, Pêgas MM, Fernández TL, Magalhães M, Schöntog TG, Lago DC, et al. Inhibitory action of aqueous garlic peel extract on the corrosion of carbon steel in $\mathrm{HCl}$ solution. Corrosion Science. 2012;65:360-366.

4. Rani BEA, Basu BBJ. Green inhibitors for corrosion protection of metals and alloys: An overview. International Journal of Corrosion. 2012;2012:380217.

5. de Barros IB, Kappel MAA, Santos PM, Veiga Junior VF, D'Elia E, Bastos IN. The inhibitory action of Bauhinia purpurea extracts on the corrosion of carbon steel in sulfuric acid medium. Materials Research. 2016;19(1):187-194.

6. Roberge PR. Corrosion inhibitors. In: Roberge PR, ed. Handbook of Corrosion Engineering. New York: McGraw-Hill; 1999.

7. Custódio DL, Veiga Junior VF. Lauraceae alkaloids. RCS Advances. 2014;4(42):21864-21890.

8. Gottlieb OR, Magalhães MT. Essential oil of the bark and wood of Aniba canelilla. Perfumery and Essential Oil Record. 1960;51:69-70.

9. Oger JM, Richome P, Guinaudeau H, Bouchara JP, Fournet A. Aniba canelilla (H. B. K.) Mez essential oil: analysis of chemical constituents, fungistatic properties. Journal of Essential Oil Research. 1994;6(5):493-497.

10. Taveira FSN, de Lima WN, Andrade EHA, Maia JGS. Seasonal essential oil variation of Aniba canelilla. Biochemical Systematics and Ecology. 2003;31(1):69-75.

11. Silva JK, Sousa PJ, Andrade EH, Maia JG. Antioxidant capacity and citotoxicity of essential oil and methanol extract of Aniba canelilla (H. B. K.) Mez. Journal of Agricultural Food Chemistry. 2007;55(23):9422-9426.

12. Lima AB, Santana MB, Cardoso AS, da Silva JK, Maia JG, Carvalho JC, et al. Antinociceptive activity of 1-nitro-2phenylethane, the main component of Aniba canelilla essential oil. Phytomedicine. 2009;16(6-7):555-559.

13. Oger JM, Duval O, Richome P, Bruneton J, Guinaudeau H, Fournet A. (R)-(+)-Noranicanine, a new type of trioxygenated benzylisoquinoline. Isolation and synthesis. Heterocycles. 1992;34(1):17-20

14. Oger JM, Fardeau A, Richome P, Guinaudeau H, Fournet A. Nouveaux alcaloïdes isoquinoléiques isolés d'une Lauracea boliviene: Aniba canelilla H.B.K. Canadian Journal of Chemistry. 1993;71(8):1128-1135.
15. Chevalier M, Robert F, Amusant N, Traisnel M, Roos C, Lebrini M. Enhanced corrosion resistance of mild steel in 1 M hydrochloric acid solution by alkaloids extract from Aniba rosaeodora plant: Electrochemical, phytochemical and XPS. Electrochimica Acta. 2014;131:96-105.

16. Ikeuba AI, Okafor PC, Ekpe UJ, Ebenso EE. Alkaloid and nonalkaloid ethanolic extracts from seeds of Garcinia kola as green corrosion inhibitors of mild steel in $\mathrm{H}_{2} \mathrm{SO}_{4}$ solution. International Journal of Electrochemical Science. 2013;8(5):7455-7467.

17. de Barros IB, Moscoso HZL, Custódio DL, Veiga Junior VF, Bastos IN. Aniba canelilla as corrosion inhibitor of carbon steel. Revista Virtual de Química. 2015;7(5):1743-1755.

18. Ferreira ES, Giacomelli C, Giacomelli FC, Spinelli A. Evaluation of the inhibitor effect of L-ascorbic acid on the corrosion of mild steel. Materials Chemistry and Physics. 2004;83(1):129-134.

19. Orazem ME, Tribollet B. Electrochemical Impedance Spectroscopy. New Jersey: John Wiley \& Sons; 2008.

20. Córdoba-Torres P, Mesquita TJ, Nogueira RP. Influence of geometry-induced current and potential distributions on the characterization of constant-phase element-phase behavior. Electrochimica Acta. 2013;87:676-685.

21. Kerner Z, Pajkossy T. Impedance of rough capacitive electrodes: the role of surface disorder. Journal of Electroanalytical Chemistry. 1998;448(1):139-142.

22. Rammelt U, Reinhard G. On the applicability of a constant phase element (CPE) to the estimation of roughness of solid metal electrodes. Electrochimica Acta. 1990;35(6):1045-1049.

23. Satapathy AK, Gunasekaran G, Sahoo SC, Amit K, Rodrigues PV. Corrosion inhibition by Justicia gendarussa plant extract in hydrochloric acid solution. Corrosion Science. 2009;51(12):28482856.

24. de Souza FS, Spinelli A. Caffeic acid as a green corrosion inhibitor for mild steel. Corrosion Science. 2009;51(3):642-649.

25. Anupama KK, Ramya K, Shainy KM, Joseph A. Adsorption and electrochemical studies of Pimenta dioica leaf extracts as corrosion inhibitor for mild steel in hydrochloric acid. Materials Chemistry and Physics. 2015;167:28-41.

26. El Hamdani N, Fdil R, Tourabi M, Jama C, Bentiss F. Alkaloids extract of Retama monosperma (L.) Boiss. Seeds used as novel eco-friendly inhibitor for carbon steel corrosion in $1 \mathrm{M} \mathrm{HCl}$ solution: Electrochemical and surface studies. Applied Surface Science. 2015;357(Pt A):1294-1305.

27. Chauhan LR, Gunasekaran G. Corrosion inhibition of mild steel by plant extract in dilute $\mathrm{HCl}$ medium. Corrosion Science. 2007;49(3):1143-1161.

28. Abboud Y, Tanane O, El Bouart A, Salghi R, Hammouti B, Chetouani A, et al. Corrosion inhibition of carbon steel in hydrochloric acid solution using pomegranate leave extracts. Corrosion Engineering, Science and Technology. 2016;51(8):557565. 